\title{
Prey Selectivity and Diet Partitioning of Juvenile Salmon in Coastal Waters in Relation to Prey Biomass and Implications for Salmon Early Marine Survival
}

\author{
Elizabeth A. Daly ${ }^{1}$, Richard D. Brodeur ${ }^{2}$, Cheryl A. Morgan ${ }^{1}$, Brian J. Burke ${ }^{3}$, and David D. Huff ${ }^{2}$ \\ ${ }^{1}$ Cooperative Institute for Marine Resources Studies, Oregon State University, Newport, Oregon 97365, USA \\ ${ }^{2}$ NOAA Fisheries, Northwest Fisheries Science Center, Newport, OR 97365, USA \\ ${ }^{3}$ NOAA Fisheries, Northwest Fisheries Science Center, Seattle, WA 97365, USA
}

Keywords: trophic ecology, prey, diet overlap, selectivity, Chinook salmon, coho salmon, California Current

Feeding conditions for juvenile salmon during their early ocean residence have been shown to be critical to their growth and survival, although direct sampling of their food availability has been limited (Brodeur et al. 2011). Increased understanding of prey dynamics during the early marine period of juvenile salmon could help us to better understand when increased competition may be occurring between salmon that eat at similar trophic levels. Juvenile coho (Oncorhynchus kisutch) and Chinook (Oncorhynchus tshawytscha) salmon typically consume age-zero juvenile fish, crab larvae, krill, and amphipods during their early marine residence, many of which are difficult to quantitatively assess using typical plankton gear (Brodeur et al. 2011). In May 2017 and 2018, as part of the National Oceanic and Atmospheric Administration's Juvenile Salmon Ocean and Ecosystem Survey (JSOES), we collected juvenile salmon and their prey concurrently in coastal waters off Washington, USA by adding a fine mesh liner to the surface trawl net that has previously been used to sample juvenile salmon. The primary focus of the JSOES survey is to better understand the early marine period of Endangered Species Act (ESA) listed salmon and how changes in ocean conditions may impact their marine survival (Daly et al. 2013; Burke et al. 2013; Crozier et al. 2021). The goal of our study was to specifically examine prey environment, diet overlap, and how salmon utilized the available prey in 2017 and 2018.

Ocean conditions during the winter and spring previous to juvenile salmon outmigration have been correlated with first summer salmon prey community and biomass, salmon diets, and salmon size, growth, body condition, and subsequent adult returns (Pearcy 1992; Daly and Brodeur 2015; Brodeur and Daly 2019). Sea surface ocean temperatures in 2017 were warm, and we observed low catches at every trophic level measured (Wells et al. 2017), resulting in a poor ocean productivity year for salmon. Ocean temperatures were cooler in 2018 than in 2017, although still above the long-term average, and numerous ecosystem indicators in 2018 suggested better conditions than 2017 (fair ocean condition year). Ocean ecosystem indicator rankings for 2017 and 2018 are available at https://www.fisheries.noaa.gov/west-coast/science-data/ocean-ecosystem-indicators-pacific-salmon-marinesurvival-northern.

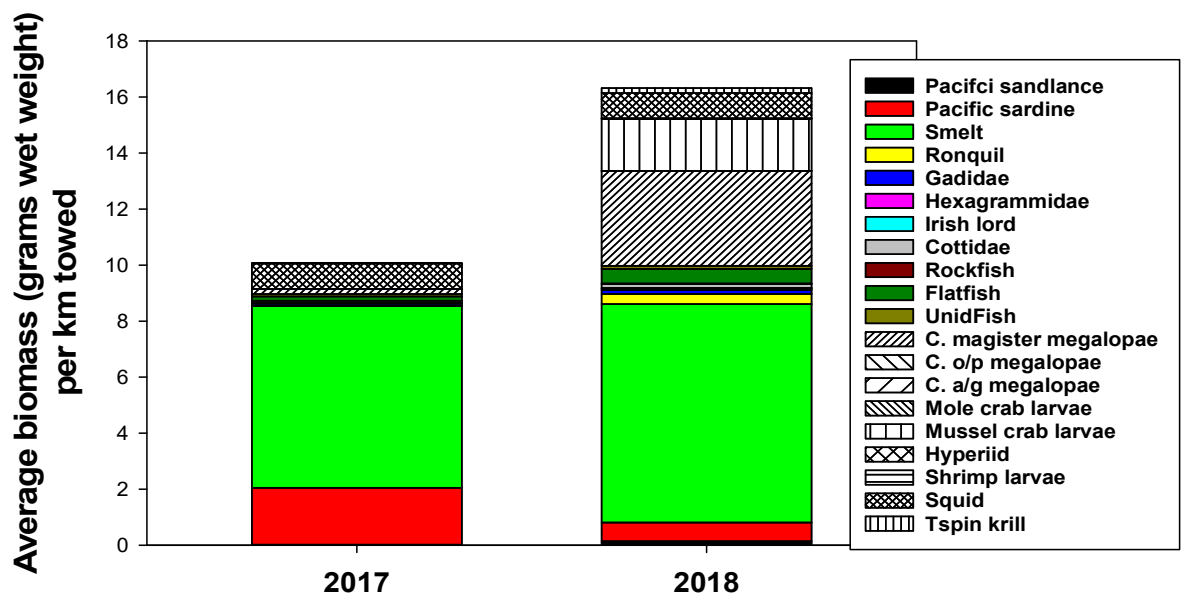

Fig. 1. Average biomass (grams wet weight per km towed) of potential prey taxa of juvenile fish (solid colors) or invertebrate taxa (black and white patterns) in 2017 and 2018.

Non-metric multidimensional scaling ordination (NMDS) was used to visually compare the prey field biomass in 2017 and 2018, and the Analysis of similarities (ANOSIM) was used to test for significant differences between the years (Clarke 1993). The prey fields were significantly different from each other (ANOSIM, Global $r=0.152 ; p$ $=0.002$ ), and the average prey biomass per km towed was higher in 2018 mostly due to increased catches of crab 
larvae (Fig. 1). The diversity of prey was also higher in 2018 (Shannon $\left.H^{\prime}=1.15\right)$ than in $2017\left(H^{\prime}=0.56\right)$. The biomasses of fish in the prey field were only slightly higher in 2018 , but invertebrates were much more prevalent in 2018.

To compare the juvenile salmon diet composition to the prey fields, we calculated the diet composition on prey that were recently consumed (prey conditions of 3 or 4; see Brodeur et al. (2011) for methodology) and we averaged these diets across the juvenile salmon at each station. The prey field biomass at a sampling station was converted to percentage compositions for comparison to juvenile coho and Chinook salmon diets. Overall, the salmon diets were similar to each other in 2017 but not 2018. The salmon were selective on specific taxa that were rare in the environment, and also avoided consuming some common taxa found in the environment. Specifically, in 2017, Chinook and coho salmon ate similar diets to each other (ANOSIM; Global $r=0.041 ; p=0.24$ ), yet the diets were significantly different from the prey composition in the environment (ANOSIM; Global $r=0.445 ; p=0.001$; Fig. 2). In 2018, the diets of the two species were significantly different from each other and also from the prey in the environment (ANOSIM; Global $r=0.474 ; p=0.001$; Fig. 2). Percent Similarity Index (PSI) was used to calculate how closely the diet and prey composition were to each other, with a resulting value $>60 \%$ indicating high overlap (Wallace and Ramsey 1983). Percent Similarity Index between average station diet and available prey composition was low for coho and Chinook salmon in both years (all values $<16 \%$ ) as the salmon were consuming taxa that were rarely or not caught in the trawl or were rarely/not consuming taxa that were the dominant taxa caught in the environment.

\section{a)}

\section{b)}

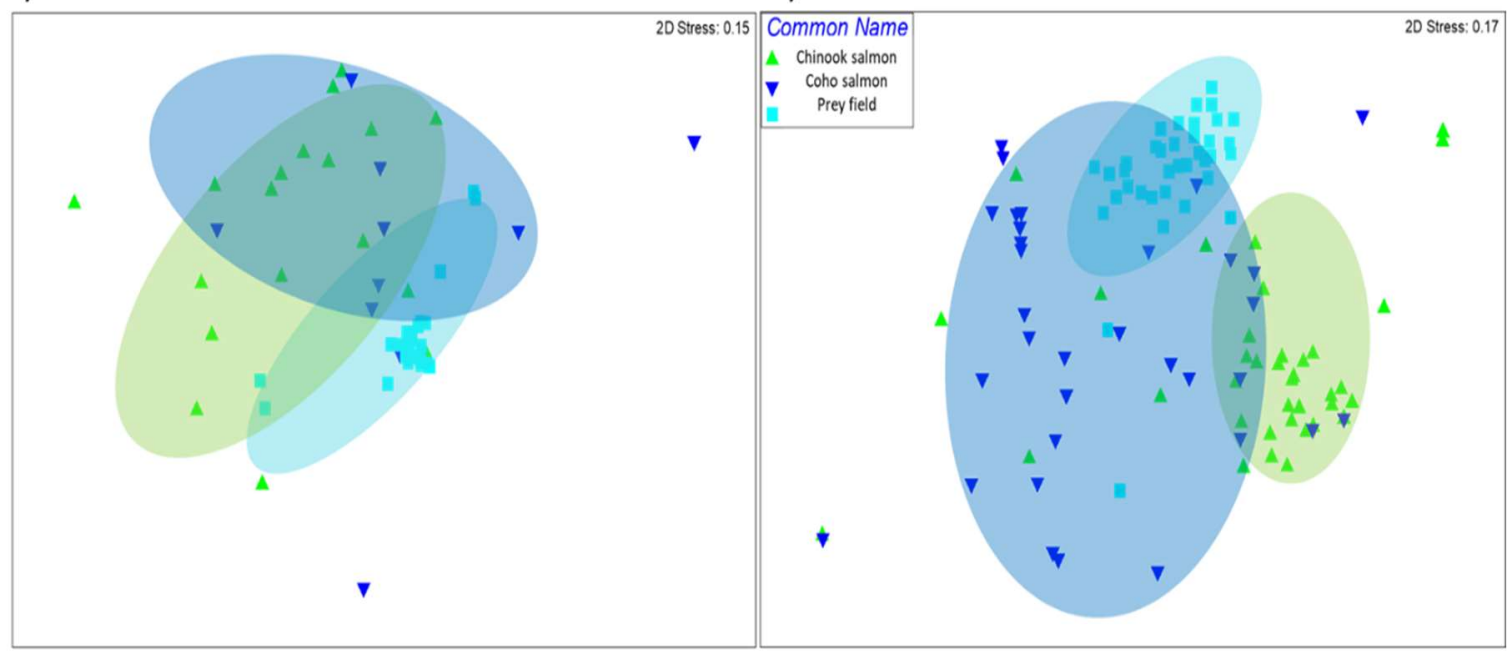

Fig. 2. Non-metric multidimensional scaling ordination (NMDS) plot of station-averaged juvenile salmon diet composition and the station prey field composition for 2017 (a) and 2018 (b). Ellipses represent the spatial area of the Chinook salmon diets (green), coho salmon diets (blue) and the prey field (aqua).

By visually comparing the frequency of taxa occurring at a sampling station in the environment and the diets (Fig. 3), we observe that yearling coho and Chinook salmon infrequently fed upon fish such as juvenile smelts (Osmeridae), ronquils, and flatfishes. Juvenile smelt were present in the environment at almost all (2017) or all (2018) of the stations sampled, yet they were eaten only at around $20 \%$ of the stations for Chinook salmon and about $40 \%$ of the stations for coho salmon (Fig. 3). Juvenile flatfishes were also sampled in the environment at almost all of the stations, yet they were present in the diets of Chinook salmon at only a few stations in both years and were found not at all (2017) or rarely (2018) in coho salmon diets. Juvenile sculpins (Cottidae) were consistently selected and consumed by the salmon (eaten at $>60 \%$ of the stations sampled), yet they were rarely caught in the environment (2018) or not caught at all (2017; Fig. 3). For invertebrate prey, both salmon species increasingly ate Cancer spp. larvae and coho salmon shrimp larvae (Pandalidae) and hyperiid amphipods (Amphipoda) relative to the frequency of these taxa in the environment, although the fine mesh liner in the net may not be able to quantitatively retain such small taxa accurately. Overall, juvenile salmon diets had higher congruency with the prey in the environment in 2018 than in 2017, when there was both higher biomass and diversity of prey available. 

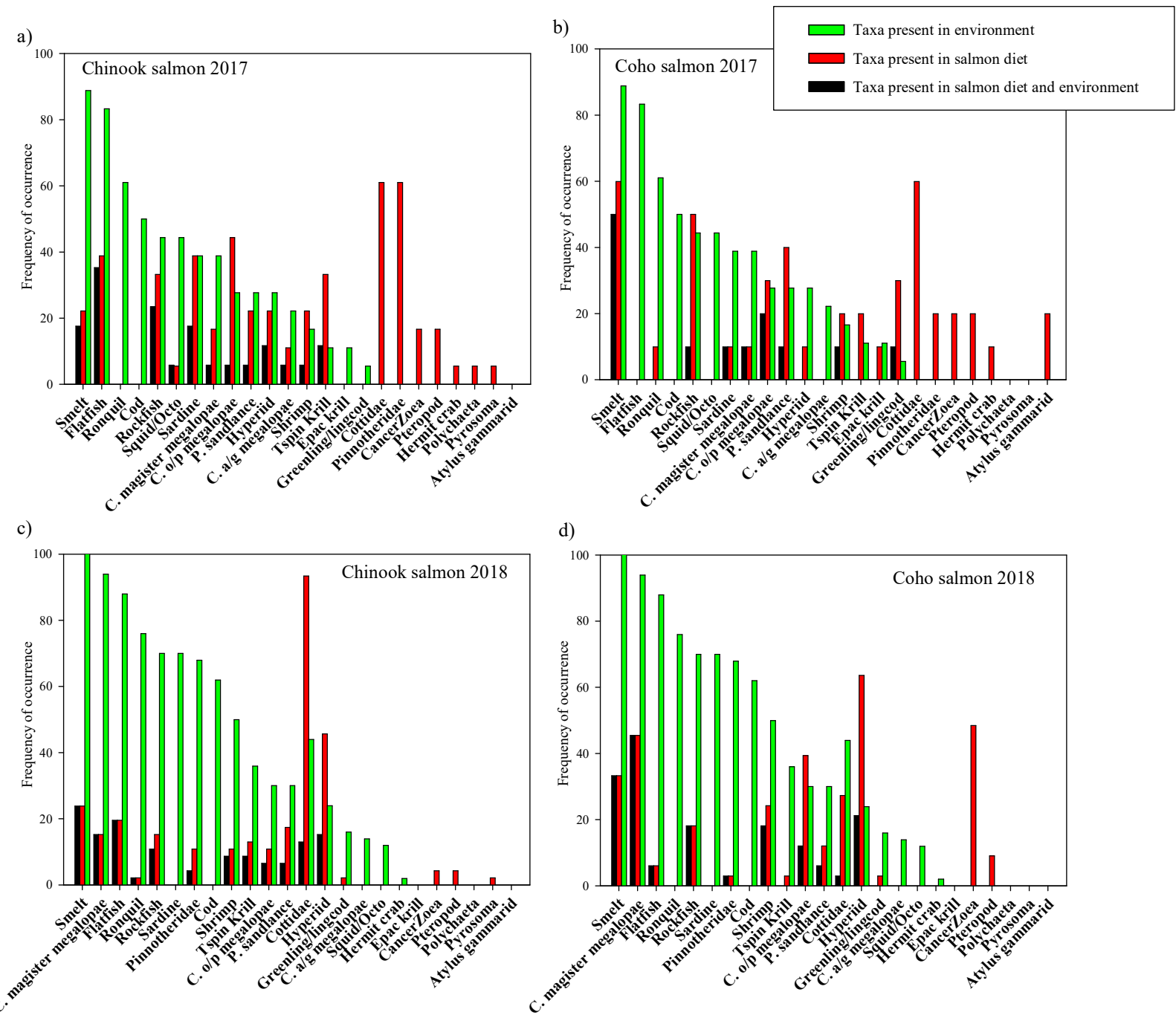

Fig. 3. Station frequency of occurrence of the presence of taxa in the environment (green), juvenile salmon diets (red), and presence of the taxa at the same station in the environment and the salmon diets (black) for Chinook salmon in 2017 (a) and 2018 (c) and coho salmon in 2017 (b) and 2018 (d).

While we observed differences in the salmon diets and the prey environment in 2017 and 2018, there was little difference in salmon marine survival based upon adult returns between the two years. Yearling Chinook salmon returned from ocean outmigration years 2017 and 2018 in extremely low numbers, and coho salmon returned in slightly higher numbers in 2018 than in 2017. Although any comparison involving only two years is insufficient to draw definitive conclusions, our results are consistent with an emerging hypothesis that diet partitioning may occur when food resources are plentiful, and interspecific competition for the same prey taxa may occur when food resources are scarcer. In the future, looking at prey fields of salmon and their feeding selectivity during more productive ocean conditions than were observed in 2017-2018 could help us to better understand the trophic dynamics and survival of juvenile salmon during their early marine period and contribute to forecasting subsequent salmon returns.

Acknowledgements-This research was funded by the Bonneville Power Administration. We thank all the crew and scientists who assisted in the sampling and processing of the samples. 


\section{REFERENCES}

Brodeur, R.D., and E.A. Daly. 2019. Changing ocean conditions and some consequences for juvenile salmon feeding in coastal waters. N. Pac. Anadr. Fish Comm. Tech. Rep. 15: 113-116. (Available at https://npafc.org)

Brodeur, R.D., E.A. Daly, C.E. Benkwitt, C.A. Morgan, and R.L. Emmett. 2011. Catching the prey: sampling juvenile fish and invertebrate prey fields of juvenile coho and Chinook salmon during their early marine residence. Fish. Res. 108: 65-73.

Burke, B.J., W.T. Peterson, B.R. Beckman, C.A. Morgan, E.A. Daly, and M. Litz. 2013. Multivariate models of adult Pacific salmon returns. PLoS One 8(1): e54134.

Clarke, K.R. 1993. Non-parametric multivariate analysis of changes in community structure. Austral Ecol. 18(1): 117-143.

Crozier, L.G., B.J. Burke, B.E. Chasco, D.L. Widener, and R.W. Zabel. 2021. Climate change threatens Chinook salmon throughout their life cycle. Commun. Biol. 4: 222. doi:10.1038/s42003-021-01734-w.

Daly, E.A., and R.D. Brodeur. 2015. Warming Ocean conditions relate to increased trophic requirements of threatened and endangered salmon. PLoS One 10(12): e0144066. doi:10.1371/journal.pone.0144066.

Daly, E.A., T.D. Auth, R.D. Brodeur, and W.T. Peterson. 2013. Winter ichthyoplankton biomass as a predictor of early summer prey fields and survival of juvenile salmon in the northern California current. Mar. Ecol. Prog. Ser. 484: 203-217.

Pearcy, W.G. 1992. Ocean ecology of north Pacific salmonids. Univ. Washington Press, Seattle. 179 pp.

Wallace, H.J., and S. Ramsay. 1983. Reliability in measuring diet overlap. Can. J. Fish. Aquat. Sci. 40: 347-351. Wells, B.K., 44 et al. 2017. State of the California Current 2016-17: still anything but "Normal" in the north. Calif. Coop. Ocean. Fish. Invest. Rep. 58: 1-55. 